\title{
Textese and use of texting by children with typical language development and Specific Language Impairment
}

\author{
Elma Blom ${ }^{\mathrm{a},{ }^{*}}$, Chantal van Dijk ${ }^{\mathrm{d}}$, Nada Vasić ${ }^{\mathrm{a}}$, Merel van Witteloostuijn ${ }^{\mathrm{b}}$, \\ Sergey Avrutin ${ }^{\mathrm{c}}$ \\ a Utrecht University, Department of Special Education: Cognitive and Motor Disabilities, Heidelberglaan 1, 3584 CS, Utrecht, The Netherlands \\ ${ }^{\mathrm{b}}$ University of Amsterdam, Department of Linguistics, Spuistraat 210, 1012 VT, Amsterdam, The Netherlands \\ ${ }^{c}$ Utrecht University, Department of Language, Literature and Communication, Trans 10, $3512 \mathrm{JK}$, Utrecht, The Netherlands \\ ${ }^{\mathrm{d}}$ Radboud University, Department of Linguistics, Erasmusplein 1, 6525 HT Nijmegen, The Netherlands
}

\section{A R T I C L E I N F O}

\section{Article history:}

Received 27 May 2016

Received in revised form

4 September 2016

Accepted 7 September 2016

Available online 23 September 2016

\section{Keywords:}

Texting

Specific language impairment

Grammatical development

WhatsApp

Elicited speech

\begin{abstract}
A B S T R A C T
The purpose of this study was to investigate texting and textese, which is the special register used for sending brief text messages, across children with typical development (TD) and children with Specific Language Impairment (SLI). Using elicitation techniques, texting and spoken language messages were collected from 55 children with TD and 15 children with SLI between 10 and 13 years old. The results show that text messages in the two groups were of equal length, but the children with TD used more textisms (alternative ways of spelling words) than the children with SLI. Both groups omitted words in their texting messages with similar frequencies, but while the SLI group omitted words equally frequently in texting messages and spoken language messages, omissions in the TD group were more specific to texting. This suggests that TD children omit words in texting because it is a register-specific convention, whereas children with SLI omit words regardless of the register. Socio-emotional reasons to use texting were found to be relatively important for children with SLI. This may be related to their higher level of shyness.
\end{abstract}

(C) 2016 Elsevier Ltd. All rights reserved.

\section{Introduction}

Nowadays, many school-aged children communicate by exchanging brief text messages between mobile phones through instant messenger services such as Short Message Service (SMS) or WhatsApp, henceforth referred to as texting. An intriguing aspect of texting is the use of a special register called 'textese', which is characterized by unconventional spelling and grammatical shortcuts. Despite the growing body of research on texting and textese (see Verheijen, 2013; for an overview), hardly any studies have researched texting and use of textese by children with communicative challenges, such as children with Specific Language Impairment (SLI) (Conti-Ramsden, Durkin, \& Simkin, 2010; Durkin, ContiRamsden, \& Walker, 2010; Durkin, Conti-Ramsden, \& Walker, 2011).

Studying texting in this group of children in comparison with

\footnotetext{
* Corresponding author.

E-mail addresses: W.B.T.Blom@uu.nl (E. Blom), M.T.G.vanWitteloostuijn@uva.nl (M. van Witteloostuijn), S.Avrutin@uu.nl (S. Avrutin).
}

typically developing children (TD) provides insight into the effects of SLI across modes of communication, including computermediated communication. It also sheds light on the question as to whether the use of textese is associated with poor or with welldeveloped language skills (Crystal, 2008). In spoken language, children with SLI stand out because their language resembles the speech of younger children and is characterized by word finding problems, the omission of words and use of short utterances (Leonard, 2014). In texting, omitting words is allowed, hence in text messages the language deficit of children with SLI may be less obvious than in spoken interactions, making texting a potentially attractive means of communication for them. While this has been suggested for adolescents with SLI (Durkin, Conti-Ramsden, \& Walker, 2009), virtually nothing is known about the texting behavior and preferences of younger children with SLI. The aim of the present study was to explore texting and textese in a small sample of Dutch children with SLI between the ages of 10 and 13, in comparison to a larger sample of children with typical development (TD) and a child-by-child matched TD sample. 


\subsection{Texting and textese}

When mobile phones were introduced, text messages had to be paid and were limited to 160 characters (SMS). This limitation has become irrelevant with cost-free, web-based applications such as WhatsApp, which is a cross-platform instant messaging application for smartphones. However, although the cost or the number of characters is no limitation anymore, time remains a relevant restriction as text messages are often sent fast explaining why textese still exist. Many characteristics of textese indeed suggest that the main goal of texting is to obtain high information value in the fastest and most resource-efficient way. For instance, there is a variety of textisms that lead to greater efficiency on the side of the producer because they are reductions at the word-level, such as contractions (tmrw for 'tomorrow'), phonological replacements (thru for 'through'), initialisms (ttyl for 'talk to you later'), clippings (goin for 'going'), or single letter/number homophones ( $c$ for 'see', 4 for 'for'). Other textisms, such as repeating letters to mirror lengthening (sooooo for 'so') or accent stylizations (gonna for 'going') (Verheijen, 2013) can be less well understood from the perspective of resource-efficiency and are phonetic realizations of spoken language varieties. As such, they carry pragmatic information and add to the information value, which is particularly important in the absence of face-to-face interaction. Besides reductions at the word-level, texting is characterized by reductions at the sentence-level (am going out now. want to come?). Again, the main goal here seems to be to maintain the meaning of the sentence and use as little time and space as possible.

The above examples show that textese transgresses standard orthographic conventions and grammatical rules, which has led to debates and concerns. Two quotes illustrate the two opposing views. According to Sutherland (2002), texting language is "thin and unimaginative .... mask[ing] dyslexia, poor spelling skills and mental laziness" while Thurlow (2003) states that texting language is "communicatively adept", "creative" and has a "robust sense of play". ${ }^{1}$ Some suggest that textese is a form of "linguistic whateverism" (Baron, 2008, p. 169), which refers to an attitude that is primarily marked by indifference regarding linguistic consistency, whereas others identify principles that underlie the genre (Crystal, 2010). For instance, consonants are more often maintained compared to vowels because consonants are more usable than vowels for the identification of the intended meaning (Nespor, Peña, \& Mehler, 2003). Along similar lines, it may be expected that sentence-level omissions comprise more often function words than lexical words, given that lexical words are commonly characterized having a more specific or detailed semantic content than function words and carry the principal meaning of a sentence (Corver \& Van Riemsdijk, 2001, pp. 1-19).

The opposing views on positive versus negative effects of texting on literacy are reflected in studies about children and adolescents' use of textese. It has been suggested that in education, learners should be informed about the differences between textese and standard grammar, to prevent detrimental effects of frequent texting (Cingel \& Sundar, 2012, p. 1317). Some findings indeed suggest negative associations between texting measures and literacy related outcomes (Plester, Wood, \& Bell, 2008; Wood, Kemp, \& Waldron, 2014) and grammatical abilities (Cingal \& Sundar, 2012; Kemp, Wood, \& Waldron, 2014). However, most studies show positive correlations between texting measures and literacy

\footnotetext{
${ }^{1}$ It may be worth noting that Sutherland and Thurlow have a distinctively different background (respectively English literature and communication), and that Sutherland's quotes are derived from an article published in a non-academic venue (Guardian).
}

outcomes and demonstrates that children who text more and use more textese score better at assessments of literacy skills (Bernicot, Goumi, Bert-Erboul, \& Volckaert-Legrier, 2014; Bushnell, Kemp, \& Martin, 2011; Coe \& Oakhill, 2011; Kemp \& Bushnell, 2011; Plester et al., 2008; Plester, Lerkkanen, Linjama, Rasku-Puttonen, \& Littleton, 2011; Plester, Wood, \& Joshi, 2009; Wood, Meachem, Bowyer, Jackson, Tarczynski-Bowles, \& Plester, 2011; Wood, Jackson, Hart, Plester, \& Wilde, 2011; see also Verheijen, 2013; for an overview) and no (Wood, Kemp, \& Waldron, 2014; Wood, Kemp, Waldron, \& Hart, 2014b) or positive associations between texting measures and grammatical skills (Van Dijk, van Witteloostuijn, Vasić, Avrutin, \& Blom, 2016).

Nearly all studies on texting and textese have focused on TD children. A handful of studies have compared texting behaviors and textese across individuals with TD and developmental dyslexia (Hsu, 2013; Simoës-Perlant et al., 2012; Veater, Plester, \& Wood, 2011), driven by the observation of Plester et al. (2009) that texting language is related to good performance in orthography. However, texting is a genre that, despite its written form, shares at least as many properties with spoken language as it shares with written language (Crystal, 2010). For instance, it is time-bound, spontaneous, loosely structured, and interactive. Therefore, it is also relevant to investigate texting and textese in children who have persistent difficulties with spoken language, like children with SLI (Durkin et al., 2011).

\subsection{Specific Language Impairment}

SLI is a language disorder that affects about $5-7 \%$ of the population (Tomblin et al., 1997). The effects of SLI are heterogeneous: different subdomains of language can be affected and the symptoms vary in severity (Leonard, 2014; Schwartz, 2009). One domain that is typically influenced by the impairment is grammar and the ability to use complex and well-formed sentences. For instance, in spoken language, children with SLI use shorter sentences than their peers with TD and they omit words. By far, most research on SLI has focused on the spoken modality. Dockrell, Lindsay, Mackie, and Connolly (2007) analyzed the written language of children with SLI and observed that, amongst other differences, 10 -year olds with SLI produce shorter texts than their TD peers, suggesting that the weaknesses of children with SLI are not limited to talking and understanding speech.

In a series of studies, Durkin and colleagues explored various aspects of computer-mediated communication (CMC) - an umbrella notion covering email, MSN, SMS, Facebook, WhatsApp - in groups of adolescents with TD and SLI. Durkin, Conti-Ramsden, Walker, and Simkin (2009) found that the majority of the adolescents with SLI in their study used CMC, and they sent the same number of messages and spent a similar amount of time using CMC as their peers with TD. Non-CMC-users had low language and literacy skills, but in the subsample of CMC-users language and literacy outcomes were not predictive of CMC engagement. Linguistic reasons for using CMC (e.g., not worry about spelling, typing instead of talking, lots of time or write and read messages) were relatively important for participants with SLI, while social reasons were equally important in the two groups. Comparisons of SMS messages revealed that the messages sent by adolescents with SLI were shorter than those of their peers with TD and contained fewer textisms (Durkin et al., 2011). Like the studies by Durkin and colleagues (Durkin et al., 2009, 2011), we investigated how SLI affects texting, but in contrast to these previous studies, our study was focused on children instead of adolescents. 


\subsection{Research questions and predictions}

The aim of the study was to investigate texting and textese in Dutch children with TD and SLI and to compare properties of texting and spoken language in the two groups. Three research questions were formulated for the study. The first research question is in (1).

(1) Do the text messages of children with TD and SLI differ from each other?

Based on Durkin et al. (2011) we expected that children with SLI would write shorter text messages and use fewer textisms than their peers with TD, but would possibly omit equally many words, albeit for (partly) different reasons. In order to investigate this latter issue, the research question in (2) was formulated.

(2) Are omissions specific for texting, and is this different for TD and SLI?

It was expected that children with TD would omit more in texting than in speech, in contrast with the children with SLI who may show no difference between the frequency of omissions across speech and texting. This comparison is especially relevant in light of the idea that texting masks weak language abilities (Sutherland, 2002). If weak language abilities cause children to leave out words in text messages, it would be expected that they leave out words to the same extent in spoken language. However, if children omit words in texting because of the special register, no such overlap is expected. While the former may be the case for SLI, the latter may hold for children with TD.

The third research question in (3) addressed children's motivation to use texting.

(3) Is children's use of texting driven by linguistic or socioemotional reasons, and is this different for children with TD and SLI?

Social factors are stronger predictors of texting frequency than language skills, both for individuals with TD and SLI (ContiRamsden et al., 2010). However, children with SLI may have a relatively stronger linguistic motivation for the use of texting as opposed to the use of spoken language; in texting they may stand out less and have to care less about forming full-fledged sentences than in spoken face-to-face conversations (Durkin et al., 2010).

\section{Method}

\subsection{Participants}

In total, 55 children with TD aged $10-13(M=11.70, S D=0.69)$ and 15 children with SLI aged $10-13(M=12.15, S D=0.87)$ were tested. Children with TD were recruited from grade 5 and 6 in six primary schools located in the Netherlands and had no apparent language problems as reported by their teacher and confirmed in the parental questionnaire. Children with SLI attended grade 5 and 6 in three special education schools for children with speech and language problems and had been previously diagnosed within their school. In the Netherlands, children are diagnosed with SLI and admitted to special educational services if they score at least two SD below the mean on a standardized language assessment test battery or score at least 1.5 SD below the mean on two out of four predefined subscales that are assessed with at least two appropriate measures. All children with SLI that were included in this study met these criteria. Moreover, they did not have a hearing impairment or intellectual disability that could explain their language impairment (Leonard, 2014). Children with an IQ $<80^{2}$, a diagnosis of any additional disorder, such as autism or $\mathrm{AD}(\mathrm{H}) \mathrm{D}$, and/

\footnotetext{
${ }^{2}$ Except for one child with SLI who had a nonverbal IQ score of 79.
}

or children who were raised bilingually were not included in the present sample.

Two comparisons were made between TD and SLI. First, the SLI sample was compared with the full TD sample. Then, a comparison was drawn between the SLI sample and a smaller but carefully matched TD sample. The second comparison was added to control for differences between the TD and SLI sample, and ensure validity of the outcomes. The full TD sample contained 27 girls and 28 boys and the SLI sample 8 girls and 7 boys. In the TD sample seven children (12.72\%) and in the SLI sample two children (13.33\%) were diagnosed with dyslexia. Comparisons between the two groups on general background measures showed that the children with SLI were slightly older than the children in the TD group, $F(1,68)=4.51$, $p=0.04, \eta^{2}=0.06$, had lower nonverbal IQ scores as measured using the short version of the Wechsler Nonverbal intelligence scale (WNV; Wechsler \& Naglieri, 2008), $F(1,68)=13.50$, $p<0.0005, \eta^{2}=0.17$, and lower socio-economic status (SES) $(U=168.50, p<0.0005, r=-0.42)$. Information regarding parental level of education was gathered through parental questionnaires and used as the measure of SES. This SES measure was calculated as the mean level of education of both parents on a scale from 1 (no education) to 9 (university education). Although children with SLI had lower nonverbal IQ scores and lower SES, they did not differ from the TD sample in the time they owned a mobile phone and frequency of texting. The children with SLI had lower scores on receptive vocabulary measured with the Peabody Picture Vocabulary Test (PPVT-3-NL, Schlichting, 2005), $F(1,68)=31.34$, $p<0.0005, \eta^{2}=0.32$, and grammar measured with the CELF-4-NL sentence repetition task (Kort, Schittekatte, \& Compaan, 2008), $F(1,68)=50.88, p<0.0005, \eta^{2}=0.43$. Because children with SLI also tend to have motor problems (e.g. Noterdaeme, Mildenberger, Minow, \& Amorosa, 2002) and fine motor skills may be involved in texting, children in both groups were tested with the manual dexterity subtest of the Movement ABC (Smits-Engelsman, 2010), which indeed showed higher scores for TD than SLI, $U=531$, $p=0.004, r=0.35$.

For the second comparison, a TD subsample was created consisting of TD children who were matched on a child-by-child basis with the SLI sample; so for each child in the SLI sample, a TD child was selected who resembled the SLI child on six criteria. The criteria for matching were: owning phone, ${ }^{3}$ age, nonverbal IQ dyslexia, time owning a phone and, to the extent that this was possible, SES. Each child with SLI who did not own a phone was matched with a TD child who did not own a phone, and each child with SLI and dyslexia was matched with a TD child with dyslexia. If for the criteria measured with continuous variables an exact match could not be found, the closest match was selected. Subsequently, it was statistically tested if the groups could be considered equal on these variables (age: $F(1,28)=0.41, p=0.53, \eta^{2}=0.01$; nonverbal IQ: $F(1,28)=1.15, p=0.29, \eta^{2}=0.04$; time owning a phone: $U=0.104 .50, p=0.74$; SES: $\left.F(1,28)=2.74, p=0.11, \eta^{2}=0.09\right)$. The two samples also had a similar frequency of texting $(U=97$, $p=0.53)$, the difference on the Movement ABC did not reach statistical significance $\left(F(1,28)=2.73, p=0.11, \eta^{2}=0.10\right)$ and the numbers of boys and girls were almost equal, as the matched TD sample contained 7 girls and 8 boys. As expected, the matched TD sample scored higher than the SLI sample on the PPVT $\left(F(1,28)=11.97, p=0.002, \eta^{2}=0.30\right)$ and $\operatorname{CELF}(F(1,28)=35.20$, $\left.p<0.0005, \eta^{2}=0.56\right)$.

The participant characteristics are summarized in Table 1. More

\footnotetext{
3 Two children with TD and two children with SLI did not own a phone but had access to WhatsApp or SMS through someone else's phone, for example from a family member.
} 
Table 1

Participant characteristics: means, standard deviations in parenthesis and ranges.

\begin{tabular}{|c|c|c|c|}
\hline & TD whole $(\mathrm{n}=55)$ & TD matched $(\mathrm{n}=15)$ & $\operatorname{SLI}(\mathrm{n}=15)$ \\
\hline Age & $11.7(0.69)$ & $12.0(0.65)$ & $12.1(0.83)$ \\
\hline Range & $10.4-13.3$ & $10.4-13.0$ & $10.4-13.0$ \\
\hline SES & $7.16(1.54)$ & $6.48(1.75)$ & $5.45(1.67)$ \\
\hline Range & $3-9$ & $3-9$ & $2-8$ \\
\hline NVIQ norm & $106.51(12.59)$ & $97.27(8.80)$ & $93.47(10.51)$ \\
\hline Range & $85-139$ & $85-116$ & $79-116$ \\
\hline Time owning phone & $2.3(1.16)$ & $2.3(1.28)$ & $2.1(1.28)$ \\
\hline Range & $0-4$ & $0-4$ & $0-4$ \\
\hline Texting frequency ${ }^{\mathrm{a}}$ & $28.68(30.07)$ & $26.21(17.48)$ & $21.18(17.03)$ \\
\hline Range & $0-150$ & $0-70$ & $0-50$ \\
\hline PPVT norm & $105.24(10.85)$ & $101.07(10.93)$ & $87.80(10.06)$ \\
\hline Range & $72-135$ & $72-113$ & $74-110$ \\
\hline CELF norm & $9.89(2.24)$ & $9.53(2.10)$ & $5.53(1.41)$ \\
\hline Range & $5-14$ & $5-13$ & $4-8$ \\
\hline Movement $\mathrm{ABC}$ & $1.93(1.74)$ & $2.40(1.87)$ & $3.46(1.46)$ \\
\hline Range & $0-5$ & $0-5$ & $1-5$ \\
\hline
\end{tabular}

Note: Age in years and months; Socio-economic status (SES) was measured by parental education measured on a 9-point scale (average of both parents); $\mathrm{NVIQ}=$ Nonverbal intelligence quotient score; Time owning phone in years and months; Texing frequency = frequency of texting both during a weekday and a weekend day (average); PPVT = Peabody Picture Vocabulary Test (receptive vocabulary); CELF = Clinical Evaluation of Language Fundamentals (sentence repetition); Movement $\mathrm{ABC}=$ test of fine motor skills.

${ }^{a}$ Extreme values were excluded with frequency>200: in the whole TD whole sample, 4 children were excluded, and both in the matched TD and SLI sample, 1 child was excluded.

explanation on the various measures can be found in section 2.2.

\subsection{Measures and procedures}

Children in the present study were recruited in compliance with the ethical standards regarding research with human subjects of the Utrecht University committee. Only when their parents returned signed consent forms were children included in the study. Children were individually tested in a single test session that lasted approximately $60 \mathrm{~min}$. Testing took place in a quiet room within their own primary school. The texting language task was administered at the beginning of the test session, while the spoken language task was conducted at the end. In between the two elicitation tasks, the remaining tasks were administered in two orders that were randomly assigned to participants. At the beginning of the testing session, children were handed a smartphone (Samsung Galaxy Trend Light) on which they were asked to type their text messages. During the elicitation tests (which are explained below in greater detail), the experimenter left the room in order to make the test situation more natural. In some cases, a session was divided into two parts due to school breaks or when the session was left unfinished at the end of the school day. Children were rewarded for participation with a small present. All computer-administered tasks were programmed and ran using E-Prime 2.0 software (Schneider; Eschman, \& Zuccolotto, 2012).

\subsubsection{Elicitation tasks}

Two tasks were developed to elicit text messages and one task to elicit spontaneous speech. In the first task, an elicited reply task, children were handed a mobile phone with a text message containing Dutch textisms and were asked to reply as if sending a message to a friend. The text message is shown in Table 2.
Everyday life scenarios were used to elicit both texting and spoken language in comparable tasks (e.g. Coe \& Oakhill, 2011; Hsu, 2013; Plester et al., 2011; Plester et al., 2009). Scenarios consisted of a picture and an auditorily presented story using a computer (see Appendix A for example scenarios). In the texting task, children were instructed to send a text message in response to the scenario. In the spoken language task, children responded to the scenarios by speaking out loud as if they were recording a voicemail message. In both tasks, children were instructed to respond as if they were addressing a friend. In each scenario, a similar number of syllables was used in the story, ranging from 54 to 60 . Additionally, each scenario contained 3 or 4 words that are frequently expressed as textisms (e.g. wait could be written as 'w8' or tonight as '2night' in the example scenarios). In total, eight scenarios were created and divided over four lists so that children would receive four scenarios in the texting task and four scenarios in the spoken task. Besides four items per task, the children were presented with two practice items in the texting task and one practice item in the spoken language task.

Children's responses to both tasks were transcribed, the total number of words and the number of utterances were calculated, and textisms and omitted words were categorized. Both for textisms as omissions the following procedure was used: two native speakers of Dutch would score children's messages. When they could not come to an agreement over whether something was a textism or omission they would consult a third native speaker. Words were labeled as textism when they deviated from standard spelling. Examples of textisms include the omission of letters either at the beginning or end of a word (clippings or shortenings), within a word (contractions), unconventional spelling (neologisms), letter/ number homophones, the use of English words, slang, orthographic forms of spoken Dutch (accent stylizations), and abbreviations. An

Table 2

Text message in Dutch, Dutch transcription, and English translation.

\begin{tabular}{|c|c|c|c|}
\hline Utterance & Dutch text message & Dutch transcription & English translation \\
\hline 1 & heey hgh & Hoi, hoe gaat het? & Hi, how are you? \\
\hline 2 & wr ben je & Waar ben je? & Where are you? \\
\hline \multirow[t]{2}{*}{3} & vanav afspreke? & Wil je vanavond afspreken? & Do you want to meet tonight? \\
\hline & wat wil je doen $\odot$ & Wat wil je doen? & What would you like to do? \\
\hline
\end{tabular}


absent word or morpheme was counted as omission when the presence of it was required in a 'grammatical' Dutch sentence. As it is arguable which sentential elements are essential within a sentence, we made the decision to treat the absence of a subject or (tensed) verb always as omission (such as I in wait for the bus and go in I swimming) - except in certain short expressions such as sorry or hi. Whether other words were omitted as well - such as determiners (as the in I wait for bus) - were judged by the native speakers. Consensus was always reached.

Additionally, the number of omitted words was computed and converted into a ratio measure in order to control for differences in length of the text messages or spoken utterances; for each child the number of omissions was multiplied with the number of words. Omission ratio was also calculated separately for functional elements (including bound morphemes) and lexical elements. Like omissions, textisms were converted into a ratio measure using the same formula. Textism ratio and omission ratio together represent use of textese.

\subsubsection{Questionnaires}

In the present study, two questionnaires were administered. The first questionnaire included the following questions: a) whether the child owned their own phone, b) how long they had owned the phone, c) importance of the phone, d) the type of telephone used, e) whether they used predictive texting, f) the medium used for texting, g) the frequency of texting both during a weekday and a weekend day, and h) textism use by asking the children if they write in their text messages differently from how they write in school, and if this is the case whether they can illustrate this. Frequency of texting was calculated by averaging a child's selfreported number of messages sent on a weekday and a weekend day. Time owning a phone (ToP) is a scale score, where the lowest value (1) is less than 6 months and the highest value is longer than 2 years (4). The scale for importance phone (IP) ranges from unimportant (1) to very important (5).

The second (self-reflect) questionnaire was relevant for the third research question which asked if children's use of texting is driven by linguistic or socio-emotional reasons. Firstly, this questionnaire investigated children's preference for online or offline communication. This was done by presenting children with 5 social situations (e.g. meeting new children, asking friends/parents a question) in which they were asked to indicate whether they would prefer to communicate through text messages or face-to-face conversations. Secondly, 9 questions were formulated regarding socio-emotional and linguistic reasons for the use of texting (based on Durkin et al., 2010). Examples include: "I use WhatsApp, because I like that I can use smileys to express my feelings" (socio-emotional motivation) or "I use WhatsApp, because I like that I don't have to speak" (linguistic motivation). Lastly, the self-reflect questionnaire aimed to examine children's level of shyness through 9 questions regarding online (in text messages) and offline (face-to-face spoken language) shyness (based on the Social Anxiety Scale for Adolescents (SAS-A) developed by La Greca \& Lopez, 1998). The questions on reasons for texting and children's level of shyness were answered on a scale of totally untrue (1) to totally true (5). The questionnaire included one practice item overall to ensure that the children understood the scale.

\subsubsection{Standardized measures}

The short version of the Wechsler Nonverbal intelligence scale was used as a measure of children's nonverbal intelligence (WNV; Wechsler \& Naglieri, 2008). The short version of the WNV consists of two tasks: matrix reasoning and spatial orientation. The PPVT-3NL was used to measure receptive vocabulary in Dutch. In this task, the child sees four pictures and the experimenter says a word that matches one of the four pictures. The child has to indicate which of the four pictures corresponds to the meaning of the word. The CELF-4-NL sentence repetition task was administered to assess grammar. During this task, children are required to repeat sentences of increasing complexity. The general consensus is that sentence repetition tasks reflect general language abilities and syntactic competence (e.g. Kidd, Brandt, Lieven, \& Tomasello, 2007; Klem et al., 2015). Finally, children completed the manual dexterity subtest of the movement ABC (ABC-2-NL, Henderson et al., 2010), which is a test battery designed to diagnose children with impairments in motor development. In this task, children were presented with a wooden board that contained 16 small holes, 12 of them filled with small pins. Slightly different subtests were administered depending on the age of the child, following the standard procedure of the movement $A B C$ and allowing us to use standardized scores. At age 10 , children were required to move all pins up one row. Children aged 11-13 had to turn the same rows of pins around so that the other side was facing up. The task was performed with both hands, the dominant hand first, and as quickly as possible. A stopwatch was used to record the time taken to complete the task. The results of both hands were combined into a single standardized score on a scale of $0-5$, with high scores indicating lower motor skills.

\section{Results}

\subsection{Properties of text messages: TD versus SLI}

The first research question addressed properties of text messages in the two groups. The data in Table 3 provide information on length of the messages calculated in number of utterances and words, textism ratio, and omission ratio based on both the elicited reply and the elicitation experiment.

Prior to statistical testing, we inspected the distributions of the variables. Extreme values - values more than two standard deviations above the mean - were excluded. These comprised two values for textism ratio and two values for omission ratio in the TD sample. These values were from different children. We decided to exclude these variables because the values were clearly out of range: 42.55 and 32.76 for omission ratio and 52.35 and 50 for textism ratio. Because the distributions of textism ratio and number of utterances deviated from normality, a square root transformation was applied to these variables, which led to normal distributions, according to the outcomes of a Shapiro-Wilk test (number of utterances: $p=0.01$, textism ratio: $p=0.07$ ). A one-way ANOVA with group as the between-subjects variable revealed that the TD group had a higher textism ratio than the SLI group $(F(1,66)=7.14$, $p=0.01, \eta_{p}^{2}=0.10$ ). The other variables do not differ significantly between groups. Analyses with the matched samples revealed again a between-group difference for textism ratio $(F(1,27)=4.51$,

Table 3

Number of utterances and words of text messages, textism ratio and omission ratio (elicited reply + elicitation experiment): means, standard deviations in parenthesis, ranges.

\begin{tabular}{llll}
\hline & $\begin{array}{l}\text { TD whole } \\
(\mathrm{n}=55)\end{array}$ & $\begin{array}{l}\text { TD matched } \\
(\mathrm{n}=15)\end{array}$ & $\begin{array}{l}\text { SLI } \\
(\mathrm{n}=15)\end{array}$ \\
\hline Number utterances & $15.25(3.18)$ & $15.00(2.36)$ & $14.87(5.13)$ \\
Range & $9-24$ & $12-21$ & $5-25$ \\
Number words & $67.93(21.41)$ & $62.53(19.39)$ & $61.33(19.39)$ \\
Range & $27-120$ & $37-95$ & $18-97$ \\
Textism ratio & $13.50(11.62)$ & $16.88(14.54)$ & $5.27(4.42)$ \\
Range & $0-51.35$ & $0-50$ & $0-11.90$ \\
Omission ratio & $12.95(7.72)$ & $13.53(7.87)$ & $12.84(6.44)$ \\
Range & $2.1-42.6$ & $2.13-32.76$ & $1.61-24.14$ \\
\hline
\end{tabular}


$p=0.04, \eta_{p}^{2}=0.14$ ) only and no significant difference for length in utterances, words and omission ratio.

\subsection{A closer look at omissions}

Omissions at the sentence-level (omission ratio) included different types of elements, which can be broken down into functional and lexical elements. Functional omissions outnumbered lexical omissions. Table 4 contains the group means based on the sums of omissions per child in the elicited replies and elicitation experiment.

A repeated measures ANOVA with type of omission (lexical, function) as the independent within-subjects variable and the number of omissions as the dependent variable was performed to determine if the difference between lexical and functional omissions reached significance. This analysis confirmed the higher omission rate of function words than lexical words $(F(1,69)=96.69$, $\left.p<0.0005, \eta_{p}^{2}=0.58\right)$. Functional omissions were most often personal pronouns frequently accompanied by the omission of auxiliaries as in (ik) ben onderweg '(I) am on my way' or ( $i k$ heb de) bus gemist '(I have) missed (the) bus'. Lexical omissions were nearly always omissions of main verbs in non-finite (infinitival, past participle) form, as in kan je vanavond bij mij (spelen)? 'can you (play) with me tonight?'.

To answer the second research question, omission ratio in text messages was compared with omission ratio in spoken voicemail messages collected with the elicitation experiment. The omission ratios for the two groups in the two types of task are in Table 5.

The distribution of omission ratio deviated from a normal distribution both in texting and speech; square root transformations led to a normal distribution for omission ratio in texting as shown by the outcomes of the Shapiro-Wilk test $(p=0.38)$. The distribution for omission ratio in speech clearly improved, but still contained relatively many zero values. The outcome of the Shapiro-Wilk test suggested that the distribution deviated from normality $(p=0.004)$. However, other, less stringent, indicators of normality indicated that the distribution was sufficiently normal to pursue a parametric test (skew $=-0.07$, kurtosis $=-0.26$ ). Therefore, a mixed ANOVA was conducted with type of task (texting, speech) as the within-subjects variable and group (TD, SLI) as the between-subjects variable and omission ratio as the dependent variable. For the whole TD sample, we found a main effect of $\operatorname{task}\left(F(1,68)=9.32, p=0.003, \eta_{p}^{2}=0.12\right)$ showing more omissions in text messages than in spoken language messages. In addition, an interaction between task and group $(F(1$, $68)=4.17, p=0.045, \eta_{p}^{2}=0.06$ ) was found. Subsequent separate repeated measure ANOVA tests for the two groups showed that TD children omitted more in their text messages than in their spoken

Table 4

Omissions of lexical and functional words in text messages (elicited reply + elicitation experiment): means, standard deviations in parenthesis, ranges.

\begin{tabular}{llll}
\hline & TD whole $(\mathrm{n}=55)$ & TD matched $(\mathrm{n}=15)$ & SLI $(\mathrm{n}=15)$ \\
\hline \multirow{2}{*}{ Lexical } & $2.85(1.56)$ & $3.27(1.87)$ & $2.67(1.68)$ \\
& $0-7$ & $0-6$ & $0-6$ \\
Functional & $6.47(3.66)$ & $6.80(3.47)$ & $6.07(3.62)$ \\
& $1-16$ & $2-14$ & $1-15$ \\
\hline
\end{tabular}

language messages $\left(F(1,54)=30.95, p<0.0005, \eta_{p}^{2}=0.36\right)$, while the children with SLI did not show this difference $(F(1,14)=0.30$, $\left.p=0.59, \eta_{p}^{2}=0.02\right)$. In the analyses with the matched samples, the main effect of task was significant $\left(F(1,28)=6.60, p=0.02, \eta_{p}^{2}=0.19\right)$ and the interaction effect showed a trend $(F(1,28)=3.17, p=0.09$, $\left.\eta_{p}^{2}=0.10\right)$. The medium to large effect size suggests that the interaction effect may not have reached statistical significance because of a lack of power.

\subsection{Motivation to use texting}

The third research question formulated for our study was: Is children's use of texting driven by linguistic or socio-emotional reasons, and is this different for children with TD and SLI?

In order to perform a factor analysis on the questionnaire data, we first examined the factorability of the items that addressed motivations for texting. Nearly all items correlated at least 0.3 with at least one other item, the Kaiser-Meyer-Olkin (KMO) measure of sampling adequacy was 0.77 (above the recommended value of $0.6)$, and Bartlett's test of sphericity was significant $\left(\chi^{2}\right.$ $(36)=112.63, p<0.001)$. Moreover, the diagonals of the anti-image correlation matrix were all over 0.5 , supporting the inclusion of each item in the factor analysis, and the communalities were all above 0.3. Given these overall indicators, we proceeded with all nine items. The number of factors to be extracted was set at two. The extracted factors had Eigenvalues above 1, but we decided to remove Q9, Q11 and Q19 because their difference was less than 0.20 between primary and cross-loadings, complicating the interpretability of the factors. All primary loadings of the remaining items were 0.50 or above, most cross-loadings were below 0.30 , all communalities - the proportion of variance per variable explained by the two factors - were 0.50 or above. Factor 1 explained $39.45 \%$ of the variance and Factor 2 19.91\%.

Because the items that loaded on component 1 concerned (spoken or written) language, this factor was labeled Linguistic motivation. The items that loaded on component 2 had to do with socio-emotional reasons for texting, and therefore this factor was labeled Socio-emotional motivation. A one-way ANOVA with group as the between-subjects variable (TD, SLI) and the saved factor scores as the dependent variable showed no difference between the groups on Linguistic motivation while the SLI group scored significantly higher on Socio-emotional motivation compared to the TD group both in the comparison with the whole sample $(F(1$, $\left.61)=6.68, p=0.01, \eta_{p}^{2}=0.10\right)$ and the matched sample $(F(1$, 26) $=6.37, p=0.02, \eta_{p}^{2}=0.20$ ).

Motivation to use texting could be related to shyness, which may differ between children with TD and SLI. Therefore, in a followup analysis, the nine shyness items were analyzed. All items correlated at least 0.3 with at least one other item, the KMO measure was 0.68 and Bartlett's test of sphericity was significant $\left(\chi^{2}\right.$ $(36)=145.47, p<0.0005)$, the diagonals of the anti-image correlation matrix were all over 0.5 and the communalities above 0.3 except for Q1, which was not included in further analyses. The two extracted factors explained respectively $43.14 \%$ and $15.45 \%$ of the variance. They could be interpreted as shyness in General (Component 1) and in New (Component 2) situations, hence did not

Table 5

Omission ratios in text messages and spoken messages (elicitation experiment only): means, standard deviations in parenthesis, ranges.

\begin{tabular}{|c|c|c|c|c|c|c|}
\hline & \multicolumn{2}{|c|}{ TD whole $(\mathrm{n}=55)$} & \multicolumn{2}{|c|}{ TD matched $(\mathrm{n}=15)$} & \multicolumn{2}{|l|}{$\operatorname{SLI}(\mathrm{n}=15)$} \\
\hline & Texting & Speech & Texting & Speech & Texting & Speech \\
\hline \multirow[t]{2}{*}{ Omission ratio } & $9.07(7.07)$ & $3.22(2.70)$ & $10.72(7.69)$ & $3.92(3.37)$ & $5.55(3.71)$ & 5.05 (5.09) \\
\hline & $0-32.73$ & $0-10$ & $0-27.78$ & $0-10$ & $0-11.93$ & $0-18.49$ \\
\hline
\end{tabular}


match the a priori distinction between off- and online shyness. The SLI group exhibited more general shyness than the children with TD $\left(F(1,60)=7.02, p=0.01, \eta_{p}^{2}=0.11\right)$ but no difference emerged for shyness in new situations. In the matched sample, neither of the two comparisons reached significance. An overview of the motivation and shyness items is in Appendix B. The factor loadings and communalities are listed in Appendix C.

\section{Discussion}

This experimental study aims at contributing to the growing body of research that investigates computer-mediated communication (CMC), in particular use of texting and textese in children's texting messages. Texting behavior of children with SLI is a relevant research area because of the problems this population has in the linguistic domain. The linguistic problems are expected to surface in their texting behavior. In the present study a small group of 10-13 year old children with SLI was compared with age-peers with TD.

\subsection{Comparing text messages across TD and SLI}

The text messages of the TD and SLI groups differed in use of textese measured with textism ratio. The text messages of the children with SLI contained fewer textisms than the messages of children with TD. This observation parallels findings by Durkin et al. (2009) who found that adolescents with SLI used fewer textisms than their peers with TD and it supports the hypothesis that use of textisms is associated with well-developed language abilities (Thurlow, 2003). The finding that the text messages in the SLI group were of the same length as those in the TD group was not what we expected on beforehand, but it might also indicate that the children with TD show genre-specific behavior and adhere to conventions of texting. The symptoms of SLI thus surface to some extent in texting, but may be less visible than in spoken language because the children with TD omit regularly as well, similar to the children with SLI, and their messages tend to be short, like the messages of children with SLI. Taken together, the language weaknesses of children with SLI are reflected in texting, but may be more masked than in spoken and formal written registers because in texting omissions are also frequent in the messages of children with TD.

\subsection{Comparing omissions in texting and speech}

For this study, we were particularly interested in omissions. Function words were more often omitted than lexical words. Because function words carry less meaning than lexical words, the observation that children drop function words more often than lexical words is consistent with the assumption that the goal of textese is to maintain meaning in a resource-efficient manner (Crystal, 2010). In this respect there are analogies with newspaper headlines and other special registers in which it is important to save time, space and/or processing resources. Linguists have long noticed that even in adult unimpaired speech certain omissions are possible, for example omissions of subjects in the diary style (e.g. "Got up at 7. Took shower. Left", see Haegeman, 1990). Another special register that allows omissions (in this case functional morphemes expressing tense) is the socalled Mad Magazine Register (Akmaijan, 1984), for example "Me do dishes?! Never". Other studies provide information-based analyses of omission of function words in newspaper headlines (e.g. POLICE OFFICER KILLS THE ROBBER; PRESIDENT TO VISIT CHINA NEXT MONTH, etc.) and argue that it is the economy of processing that triggers the use of such abbreviated utterances
(Avrutin, 1999; De Lange, 2008; De Lange, Vasić, \& Avrutin, 2009). Along similar lines, Avrutin (1999, 2006) makes a connection to the speech of individuals with Broca's aphasia (patients with limited processing resources) who exhibit a pattern of omission similar to that observed in the aforementioned special registers.

The main reason as to why we wanted to take a closer look at omissions is that omissions are not only a convention of textese but also a property of the speech of children with SLI (e.g., McGregor \& Leonard, 1994; Rice \& Wexler, 1996), which extends to failures to notice omissions in perception (Blom, Vasić, \& De Jong, 2014; Chondrogianni, Marinis, Edwards, \& Blom, 2015; Leonard, Miller, \& Finneran, 2009), suggesting poor syntactic knowledge. Consequently, unlike the children with TD who omit in their texting messages because it is allowed in this register, children with SLI may omit because of their syntactic impairment. This hypothesis is supported by the observation that the children with TD omitted more in texting than in speech, while the children with SLI omitted equally often in texting and speech. Thus, children with TD distinguish between registers, while the children with SLI do not seem to make this distinction, which is consistent with the idea that their omissions in texting stem from poor syntactic skills.

In order to compare texting and speech in the best possible way, a similar method was used to collect data in the two different registers. In a previous study in which we compared the texting data from the elicitation experiment with naturally produced texting messages (Van Dijk et al., 2016) we found that the elicitation method affected children's language use: textism ratio was higher in the naturally produced messages but omission ratio was not different across the two methods. By using similar methods in the two registers we try to avoid this problem.

\subsection{Linguistic and socio-emotional reasons to use texting}

In texting, children need to worry less about their language than in spoken language, which could be a reason as to why children with SLI are motivated to use texting. Also, due to the characteristics of textese, children with SLI may stand out less in texting than in spoken interaction. The findings of our study indicated that socio-emotional reasons to use texting were more important for children with SLI than for children with TD, while no difference between the two groups emerged for language-related reasons to use texting. Adolescents with SLI have higher levels of shyness compared to their peers with TD (Wadman, Durkin, \& ContiRamsden, 2009) and Durkin et al. (2010) argue that this may be a reason as to why CMC (e.g., texting) could be attractive to adolescents with SLI for interpersonal purposes. Our findings support this idea and also demonstrate that younger children with SLI tend to be shyer than their peers with TD, which may be the reason as to why socio-emotional motivations to use texting, such as being able to say things that they would not say in real-life situations or the possibility to use emoticons to express feelings, are relatively important for them. Texting as a means of communication may thus have advantages for them even though it does require the use of language.

\section{Acknowledgement}

This project was funded through Dynamics of Youth (DoY)-one of the strategic themes of Utrecht University-by a Seed Money grant (grant number SM.YI.2013.11.GM). 


\section{Appendix A}

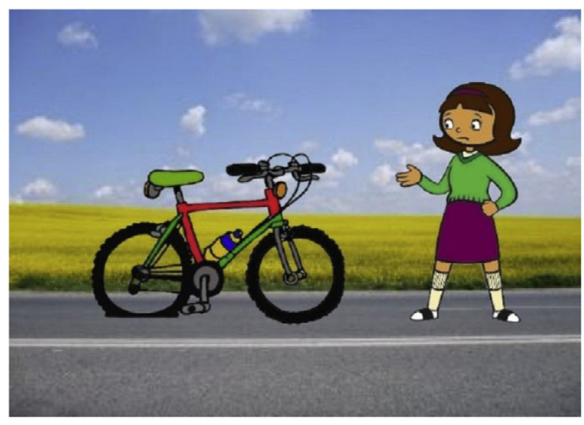

(a) Negative

You are on your way to a friend to bike to

school together, but you get a flat tire.

You explain to her what has happened.

You ask her if she can maybe wait for you.

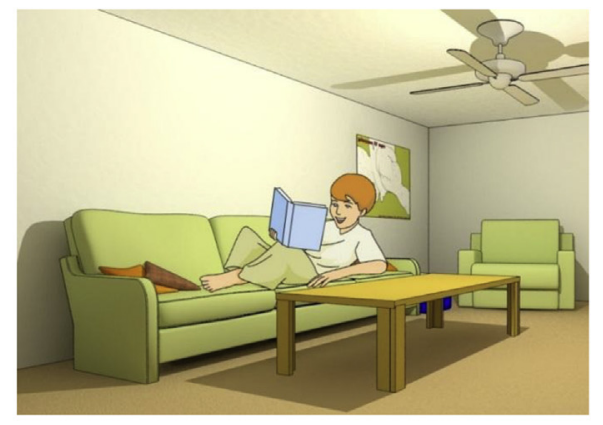

(b) Positive

You're at home tonight and are bored.

You ask a friend what he's doing.

You ask whether he maybe wants to meet

tonight to play computer games.

Fig. 1. Sample scenarios, negative (a) and positive (b).

\section{Appendix B}

Q1: Ik ben stil als ik in een groepsgesprek zit op WhatsApp 'I am silent if I am in a groupmeeting on WhatsApp'

Q2: Ik vind het makkelijk om op WhatsApp te vragen of iemand iets met mij wil afspreken 'I find it easy to ask someone on WhatsApp to meet with me'

Q3: Ik gebruik Whatsapp omdat ik het fijn vind dat ik plaatjes/ smileys kan gebruiken om mijn gevoelens te beschrijven 'I use WhatsApp because I like it that I can use pictures/smileys to describe what I feel'

Q4: Ik gebruik WhatsApp omdat ik daar dingen kan zeggen die ik in een echt gesprek niet zou zeggen 'I use WhatsApp because I can say things that I would not say in real conversations' Q5: Ik ben verlegen wanneer ik op WhatsApp met kinderen praat die ik wel goed ken 'I am shy when I task on WhatsApp with children who I know well'

Q6: Ik gebruik WhatsApp omdat veel van mijn vrienden dat doen 'I use WhatsApp because many of my friends use it' Q7: Ik gebruik WhatsApp omdat ik het fijn vind dat ik dan niet hoef te praten 'I use WhatsApp because I like it that I do not have to talk'

Q8: Ik vind het moeilijk om anderen in het echt te vragen om iets met mij af te spreken 'I find it difficult to ask someone in real situations to meet with me'

Q9: Ik gebruik WhatsApp omdat ik het fijn vind dat ik dan veel tijd heb om een bericht te schrijven 'I use WhatsApp because I like it that I have lots of time to write messages'

Q10: Ik ben zenuwachtig wanneer ik nieuwe kinderen ontmoet 'I am nervous when I meet new children'
Q11: Ik gebruik WhatsApp omdat ik me hier prettiger bij voel dan bij echte gesprekken 'I use WhatsApp because I feel better than with real conversations'

Q12: Ik ben verlegen wanneer ik op WhatsApp met kinderen praat die ik niet goed ken 'I am shy when I talk on WhatsApp with children who I do not know well'

Q13: Ik vind het moeilijk om iemand op Whatsapp te vragen om iets met mij af te spreken 'I find it difficult to ask someone on WhatsApp to meet with me' (control question, not in analyses) Q14: Ik ben stil als ik in het echt in een groep ben 'I am silent when I am in a real situation in a group'

Q15: Ik ben verlegen wanneer ik in het echt met kinderen praat die ik niet goed ken 'I am shy when in real situations I talk to children who I do not know well'

Q16: Ik gebruik WhatsApp omdat ik het fijn vind dat ik dan veel tijd heb om berichten te lezen 'I use WhatsApp because I like it that have a lots of time to read messages'

Q17: Ik gebruik WhatsApp omdat ik me daar geen zorgen hoef te maken om de spelling 'I use WhatsApp because I do have to worry about spelling

Q18: Als ik nieuwe kinderen ontmoet ben ik op mijn gemak 'When I meet new children, I am at ease' (control question, not in analyses)

Q19: Ik gebruik WhatsApp omdat ik dan minder verlegen ben dan bij echte gesprekken 'I use WhatsApp because I am less shy than with real conversations'

Q20: Als ik in een groepsgesprek zit op WhatsApp doe ik mee aan het gesprek 'When I am in a group conversation on WhatsApp I join the conversation' (control question, not in analyses) Q21: Ik ben verlegen wanneer ik in het echt met kinderen praat die ik wel goed ken 'I am shy when in real situations I talk to children who I know well' 


\section{Appendix C}

Table C1

Factor loadings and communalities for texting motivation items (Varimax rotation with loadings $<.30$ suppressed)

\begin{tabular}{llll}
\hline & Component 1 & Component 2 & Communalities \\
\hline Q7 & 0.82 & & 0.68 \\
Q17 & 0.80 & & 0.59 \\
Q16 & 0.69 & 0.33 & 0.65 \\
Q4 & & 0.76 & 0.54 \\
Q6 & & 0.70 & 0.61 \\
Q3 & 0.37 & 0.64 & 0.50 \\
\hline
\end{tabular}

\section{Table C2}

Factor loadings and communalities for shyness items (Varimax rotation with loadings $<.30$ suppressed)

\begin{tabular}{llll}
\hline & Component 1 & Component 2 & Communalities \\
\hline Q5 & 0.73 & & 0.55 \\
Q21 & 0.73 & & 0.59 \\
Q14 & 0.71 & & 0.59 \\
Q8 & 0.71 & 0.31 & 0.60 \\
Q13 & 0.56 & 0.32 & 0.42 \\
Q10 & & 0.80 & 0.66 \\
Q12 & & 0.79 & 0.68 \\
Q15 & & 0.77 & 0.61 \\
\hline
\end{tabular}

\section{References}

Akmaijan, A. (1984). Sentence type and form-function fit. Natural Language and Linguistic Theory, 2, 1-23.

Avrutin, S. (1999). Development of the syntax-discourse interface. Dordrecht: Kluwer Academic Publishers.

Avrutin, S. (2006). Weak syntax. In Y. Grodzinsky, \& K. Amunts (Eds.), Broca's region (pp. 49-62). New York: Oxford Press.

Baron, N. (2008). Always On: Language in an online and mobile world. New York: Oxford University Press.

Bernicot, J., Goumi, A., Bert-Erboul, A., \& Volckaert-Legrier, O. (2014). How do skilled and less-skilled spellers write text messages? A longitudinal study of sixth and seventh graders. Journal of Computer Assisted Learning, 30, 559-576.

Blom, E., de Jong, J., \& Vasić, N. (2014). Production and processing of subject-verb agreement in monolingual Dutch children with Specific Language Impairment. Journal of Speech Language and Hearing Research, 57, 952-965. doi: 10.1044/2014_JSLHR-L-13-0104.

Bushnell, C., Kemp, N., \& Martin, F. H. (2011). Text-messaging practices and links to general spelling skill: A study of australian children. Australian Journal of Educational \& Developmental Psychology, 11, 27-38.

Chondrogianni, V., Marinis, T., Edwards, S., \& Blom, E. (2015). Production and online comprehension of definite articles and clitic pronouns by Greek sequential bilingual children and monolingual children with specific language impairment. Applied Psycholinguistics, 36(5), 1155-1191. http://dx.doi.org/ 10.1017/S0142716414000101.

Cingel, D. P., \& Sundar, S. S. (2012). Texting, techspeak, and tweens: The relationship between text messaging and English grammar skills. New Media \& Society, 14(8), 1304-1320.

Coe, J. E. L., \& Oakhill, J. V. (2011). 'txtN is ez f u no h2 rd': The relation between reading ability and text-messaging behaviour. Journal of Computer Assisted Learning, 27, 4-17.

Conti-Ramsden, G., Durkin, K., \& Simkin, Z. (2010). Language and social factors in the use of cell phone technology by adolescents with and without specific language impairment (SLI). Journal of Speech Language, and Hearing Research, 53 , 196-208. http://dx.doi.org/10.1044/1092-4388(2009/08-0241).

Corver, N., \& Van Riemsdijk, H. (2001). Semi-lexical categories. In N. Corver, \& H. van Riemsdijk (Eds.), Semi-lexical categories: The function of content words and the content of function words. Berlin, New York: Mouton de Gruyter.

Crystal, D. (2008). Texting. ELT journal, 62(1), 77-83.

Crystal, D. (2010). The changing nature of text: A linguistic perspective. In W. van Peursen, E. D. Thoutenhoofd, \& A. van der Weel (Eds.), Text comparison and digital creativity (pp. 229-251). Leiden: Brill.

De Lange, J. N. Vasić, \& Avrutin, S. (2009). Reading between (head)lines: A processing account of article omissions in newspaper headlines and child speech. Lingua, 119(10), 1523-1540.

De Lange, J. (2008). Article omission in child speech and headlines: A processing account. Utrecht University. PhD dissertation.
Dockrell, J., Lindsay, G., Mackie, C., \& Connolly, V. (2007). Constraints in the production of written text in children with specific language impairments. Exceptional Children, 73, 147-164.

Durkin, K., Conti-Ramsden, G., Walker, A., \& Simkin, Z. (2009). Educational and interpersonal uses of home computers by adolescents with and without specific language impairment. British Journal of Developmental Psychology, 27, 197-217.

Durkin, K., Conti-Ramsden, G., \& Walker, A. J. (2010). Computer-mediated communication in adolescents with and without a history of specific language impairment (SLI). Computers in Human Behavior, 26, 176-185.

Durkin, K., Conti-Ramsden, G., \& Walker, A. J. (2011). Txt lang: Texting, textism use and literacy abilities in adolescents with and without specific language impairment. Journal of Computer Assisted Learning, 27, 49-57.

Haegeman, L. (1990). Understood subjects in English diaries. Multilingua, 9(2), $157-199$.

Hsu, J. L. (2013). Exploring the relationships between the use of text message language and the literacy skills of dyslexic and normal students. Research in developmental disabilities, 34(1), 423-430.

Kemp, N., \& Bushnell, C. (2011). Children's text messaging: Abbreviations, input methods and links with literacy. Journal of Computer Assisted Learning, 27, $18-27$.

Kemp, N., Wood, C., \& Waldron, S. (2014). Do I know its wrong: Children's and adults' use of unconventional grammar in text messaging. Reading and Writing, 27, 1585-1602.

Kidd, E., Brandt, S., Lieven, E., \& Tomasello, M. (2007). Object relatives made easy: A cross-linguistic comparison of the constraints influencing young children's processing of relative clauses. Language and Cognitive Processes, 22, 860-897. http://dx.doi.org/10.1080/01690960601155284.

Klem, M., Melby-Lervåg, M., Hagtvet, B., Lyster, S.-A. H., Gustafsson, J.-E., \& Hulme, C. (2015). Sentence repetition is a measure of children's language skills rather than working memory limitations. Developmental Science, 18, 146-154. http:// dx.doi.org/10.1111/desc.12202.

Kort, W., Schittekatte, M., \& Compaan, E. (2008). CELF-4-NL: Clinical evaluation of language fundamentals-vierde-editie. Amsterdam: Pearson assessment and information B.V.

La Greca, A. M., \& Lopez, N. (1998). Social anxiety among adolescents: Linkages with peer relations and friendships. Journal of Abnormal Child Psychology, 26, 83-94.

Leonard, L. B., Miller, C. A., \& Finneran, D. A. (2009). Grammatical morpheme effects on sentence processing by school-aged children with specific language impairment. Journal of Language and Cognitive Processes, 24, 450-478.

Leonard, L. (2014). Children with specific language impairment (2nd ed.). Cambridge: MIT Press.

McGregor, K., \& Leonard, L. B. (1994). Subject pronoun and article omissions in the speech of children with specific language impairment a phonological interpretation. Journal of Speech Language and Hearing Research, 37, 171-181. http:// dx.doi.org/10.1044/jshr.3701.171.

Nespor, M., Peña, M., \& Mehler, J. (2003). On the different roles of vowels and consonants in speech processing and language acquisition. Lingue e Linguaggio 2, 221-247.

Noterdaeme, M., Mildenberger, K., Minow, F., \& Amorosa, H. (2002). Quantitative and qualitative evaluation of neuromotor behavior in children with a specific speech and language disorder. Infant and Child Development, 11, 3-15.

Plester, B., Lerkkanen, M. K., Linjama, L. J., Rasku-Puttonen, H., \& Littleton, K. (2011). Finnish and UK English pre-teen children's text message language and its relationship with their literacy skills. Journal of Computer Assisted Learning, 27(1), 37-48.

Plester, B., Wood, C., \& Bell, V. (2008). Txt msg n school literacy: Does texting and knowledge of text abbreviations adversely affect children's literacy attainment? Literacy, 42(3), 137-144.

Plester, B., Wood, C., \& Joshi, P. (2009). Exploring the relationship between children's knowledge of text message abbreviations and school literacy outcomes. British Journal of Developmental Psychology, 27, 145-161.

Schlichting, L. (2005). Peabody picture vocabulary test-iii-NL. Amsterdam: Harcourt Assessment B.V.

Schneider, W., Eschman, A., \& Zuccolotto, A. (2012). E-Prime user's guide. Pittsburgh: Psychology Software Tools Inc.

Schwartz, R. (2009). Handbook of child language disorders. New York: Psychology Press.

Simoës-Perlant, A., Thibault, M.-P., Lanchantin, T., Combes, C., Volckaert-Legrier, O. \& Largy, P. (2012). How adolescents with dyslexia dysorthographia use texting. Written Language and Literacy, 15(1), 65-79.

Smits-Engelsman, B. (2010). Movement ABC-2 NL. Amsterdam: Pearson assessment and information B.V.

Sutherland, J. (2002). Cn u txt? The guardian, nov 11" 2002. Retrieved March 302016 from http://www.theguardian.com/technology/2002/nov/11/mobilephones2 http://www.webcitation.org/6jvWlckVe (archived link:.

Thurlow, C. (2003). Generation Txt? The sociolinguistics of young people's textmessaging. Retrieved August 212016 from (archived link: http://extra.shu.ac.uk/ daol/articles/v1/n1/a3/thurlow2002003.html http://www.webcitation.org/ 6jvY9eLj9.

Tomblin, J. B., Records, N. L., Buckwalter, P., Zhang, X., Smith, E., \& O'Brien, M. (1997). Prevalence of specific language impairment in kindergarten children. Journal of Speech Language and Hearing Research, 40, 1245-1260.

Van Dijk, C. N., van Witteloostuijn, M., Vasić, N., Avrutin, S., \& Blom, E. (2016). The influence of texting language on grammar and executive functions in primary school children. PLoS One, 11(3), e0152409. http://dx.doi.org/10.1371 
journal.pone.0152409.

Veater, H., Plester, B., \& Wood, C. (2011). Exploring the relationship between text message abbreviations and literacy skills in children with dyslexia. Dyslexia, 17, $65-71$.

Verheijen, L. (2013). The effects of text messaging and instant messaging on literacy. English Studies, 94(5), 582-602.

Wadman, R., Durkin, K., \& Conti-Ramsden, G. (2009). Self-esteem, shyness, and sociability in adolescents with specific language impairment (SLI). Journal of Speech Language and Hearing Research, 51, 938-952. http://dx.doi.org/10.1044/ 1092-4388(2008/069.

Wechsler, D., \& Naglieri, J. A. (2008). Wechsler nonverbal scale of ability. Pearson.

Wood, C., Jackson, E., Hart, L., Plester, B., \& Wilde, L. (2011). The effect of text messaging on 9- and 10-year-old children's reading, spelling and phonological processing skills. Journal of Computer Assisted Learning, 27, 28-36.

Wood, C., Meachem, S., Bowyer, S., Jackson, E., Tarczynski-Bowles, M. L., \& Plester, B. (2011). A longitudinal study of children's text messaging and literacy development. British Journal of Psychology, 102, 431-442.

Wood, C., Kemp, N., \& Waldron, S. (2014a). Exploring the longitudinal relationships between the use of grammar in text messaging and performance on grammatical tasks. British Journal of Developmental Psychology, 32, 415-429.

Wood, C., Kemp, N., Waldron, S., \& Hart, L. (2014b). Grammatical understanding literacy and text messaging in school children and undergraduate students: A concurrent analysis. Computers \& Education, 70, 271-290. 